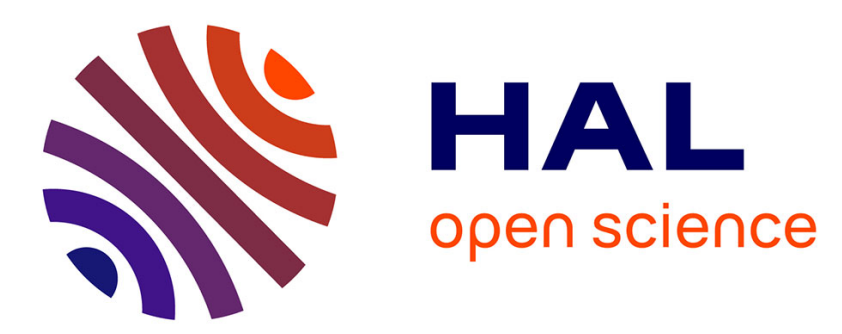

\title{
Cavity ring-down Fourier transform spectroscopy based on a near infrared optical frequency comb
}

Romain Dubroeucq, Aleksander Gluszek, Grzegorz Soboń, Lucile Rutkowski

\section{To cite this version:}

Romain Dubroeucq, Aleksander Gluszek, Grzegorz Soboń, Lucile Rutkowski. Cavity ring-down Fourier transform spectroscopy based on a near infrared optical frequency comb. Conference on Lasers and Electro-Optics/Europe, Jun 2021, online, Germany. hal-03376020

\section{HAL Id: hal-03376020 \\ https://hal.science/hal-03376020}

Submitted on 13 Oct 2021

HAL is a multi-disciplinary open access archive for the deposit and dissemination of scientific research documents, whether they are published or not. The documents may come from teaching and research institutions in France or abroad, or from public or private research centers.
L'archive ouverte pluridisciplinaire HAL, est destinée au dépôt et à la diffusion de documents scientifiques de niveau recherche, publiés ou non, émanant des établissements d'enseignement et de recherche français ou étrangers, des laboratoires publics ou privés. 


\title{
Cavity ring-down Fourier transform spectroscopy based on a near infrared optical frequency comb
}

\author{
Romain Dubroeucq ${ }^{1}$, Aleksander Głuszek ${ }^{2}$, Grzegorz Soboń $^{2}$, Lucile Rutkowski $^{1}$ \\ 1. Univ Rennes, CNRS, IPR (Institut de Physique de Rennes) - UMR 6251, F-35000 Rennes, France \\ 2. Laser \& Fiber Electronics Group, Faculty of Electronics, Wroctaw University of Science and Technology, 50-370 Wroclaw, Poland
}

Cavity ring-down spectroscopy (CRDS) based on broadband light sources offer the high sensitivity of CRDS with the advantages of a multiplex acquisition. Previous works have explored the possibility of analysing the broadband cavity decay using time-resolved FTIR and a pulsed dye laser [1], and using a virtual image phased array combined with a frequency comb source [2]. Here, we exploit the ability to lock the optical frequency comb to the ring-down cavity to ensure a high throughput for the time-resolved Fourier transform spectrometer.

The experimental setup is depicted in Fig. 1(a), where the frequency comb is a free-running Erbium-fiber source with a repetition rate of $125 \mathrm{MHz}$ [3]. The ring-down cavity has a finesse of $\sim 450$, and a length of $1.2 \mathrm{~m}$. The comb repetition rate is locked to the cavity free spectral range using the Pound-Drever-Hall technique, and the cavity transmission is analyzed using a fast-scan Fourier transform spectrometer. The optical path difference of the interferometer is calibrated using a frequency-stabilized He-Ne laser which propagates on a path parallel to the comb. A subset of the raw data acquired is shown in Fig. 1(b). The reference signal from the He-Ne laser is simultaneously recorded and sent to a digital delay generator which triggers an acousto-optic modulator and switches off the comb light. The bandwidth of the locking electronics has been adjusted in order not to be affected by the comb light chopping. The comb signal contains the successive decays measured with a $25 \mathrm{MHz}$-bandwidth photodetector at optical path differences separated by a constant step of $633 \mathrm{~nm}$. Both signals are acquired in a continuous mode at a rate of $10 \mathrm{Msample} / \mathrm{s}$ and a 3-dimensional interferogram (intensity, optical path difference, decay time) is retrieved in post-processing. Taking the fast Fourier transform of the interferograms obtained at given delays after the trigger yields the spectrum shown in Fig. 1(c), featuring the cavity decay at each spectral element with a resolution of $1.2 \mathrm{GHz}$, currently limited by the total optical path difference of $25 \mathrm{~cm}$. The ringdown obtained at $6406.8 \mathrm{~cm}^{-1}$ together with the fitted exponential decay model is plotted in Fig. 1(d). The ringdown time retrieved from the fit is $0.53 \mu \mathrm{s}$, in good agreement with the mirror reflectivity of $99.3 \%$ specified by the manufacturer (Layertec, coating 114951).
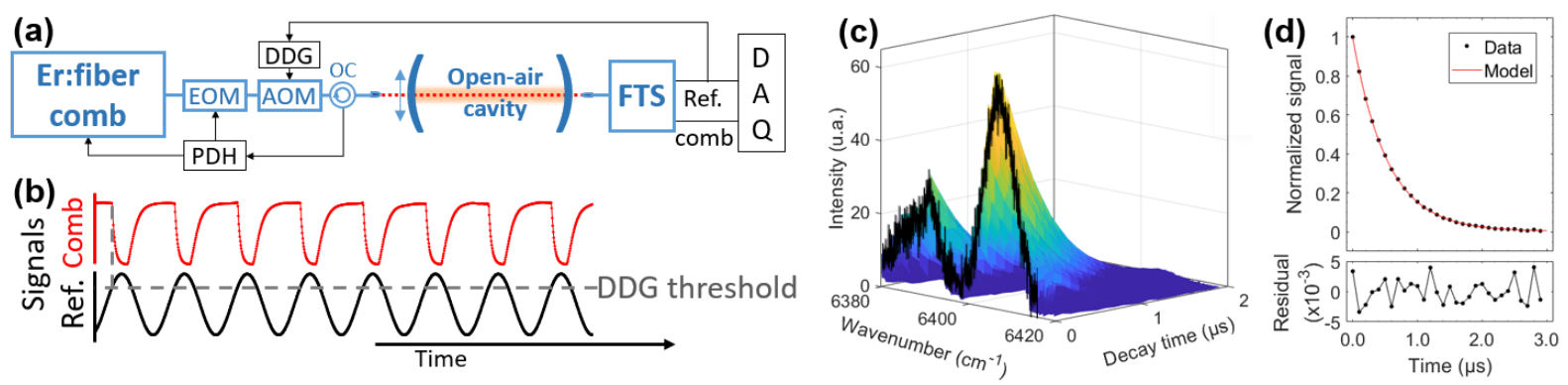

Fig. 1 (a) Experimental setup: EOM, electro-optic modulator; AOM, acousto-optic modulator; OC, optical circulator; PDH, Pound-Drever-Hall locking electronics; DDG, digital delay generator; FTS, Fourier transform spectrometer; DAQ, acquisition card. (b) Schematic of the acquisition, see details in text. (c) 3D spectrum obtained from the data, showing the spectral distribution of the decays. (d) Measured ring-down at $6406.8 \mathrm{~cm}^{-1}$ (markers) together with the fitted exponential decay model (red line) and residuum (bottom panel).

This technique will be implemented using a cavity with a higher finesse, opening up for high-sensitivity spectroscopy. The technique is also fully compatible with the sub-nominal Fourier transform spectroscopy method [4], which will allow high frequency precision and comb mode resolution.

Acknowledgements: This work is supported by the ANR project CECoSA (ANR-19-CE30-0038), the National Physics Institute (CNRS), and Rennes Metropole. G.S. and A.G. are supported by the Foundation for Polish Science (First TEAM/2017-4/39).

\section{References}

[1] M. J. Thorpe, K. D. Moll, R. J. Jones, B. Safdi, J. Ye, "Broadband cavity ringdown spectroscopy for sensitive and rapid molecular detection", Science 311(5767), 1595-1599 (2006).

[2] R. Engeln and G. Meijer, “A Fourier transform cavity ring down spectrometer”, Rev. Sci. Instr. 67, 2708 (1996).

[3] A. Głuszek, F. Senna Vieira, A. Hudzikowski, A. Wąż, J. Sotor, A. Foltynowicz, G. Soboń, "Compact mode-locked Er-doped fiber laser for broadband cavity-enhanced spectroscopy," Appl. Phys. B 126, 137 (2020).

[4] L. Rutkowski, P. Maslowski, A.C. Johansson, A. Khodabakhsh and A. Foltynowicz, "Optical frequency comb Fourier transform spectroscopy with sub-nominal resolution and precision beyond the Voigt profile”, J. Quant. Spectrosc. Radiat. Transfer, 204, 63 (2018). 